\title{
Comparison of Atherogenic Index of Plasma (AIP) Between Postmenopausal Women with Central Obesity and Postmenopausal Nonobese Women
}

\author{
Monowara Khanam ${ }^{1}$ \\ Md Aminul Haque Khan ${ }^{2 *}$ \\ Md Rezwanur Rahman ${ }^{3}$ \\ Rukhsana Parvin ${ }^{4}$ \\ Selima Akhter ${ }^{1}$ \\ Shahnila Ferdousi ${ }^{5}$
}

'Department of Biochemistry

National Institute of Kidney Diseases and Urology Dhaka, Bangladesh.

${ }^{2}$ Department of Biochemistry

Enam Medical College, Savar

Dhaka, Bangladesh.

${ }^{3}$ Department of Biochemistry

Delta Medical College

Dhaka, Bangladesh.

${ }^{4}$ Department of Medicine

Enam Medical College \& Hospital, Savar

Dhaka, Bangladesh.

${ }^{5}$ Department of Biochemistry

Dhaka Medical College

Dhaka, Bangladesh.

\section{*Correspondence to:}

Professor Md Aminul Haque Khan

Department of Biochemistry

Enam Medical College, Savar

Dhaka, Bangladesh.

Mobile: +8801552479546

E-mail:aminhkhan@yahoo.com

\begin{abstract}
Background: Following menopause there are changes in values of lipid profile parameters. Abdominal obesity has also been linked to significant metabolic abnormalities including changes in lipid parameter values. Atherogenic index of plasma (AIP) calculated as log (TG/HDL-C) has been used as some practitioners as a significant predictor of atherosclerosis. So, we designed this study to observe the pattern of lipid profile parameters and to find out AIP in postmenopausal central obese women and to compare these between postmenopausal women with central obesity and postmenopausal nonobese women. Objectives: To assess the lipid profile status and AIP of postmenopausal women with central obesity and to compare these parameters with that of postmenopausal nonobese women. Materials \& Methods: This cross sectional study was carried out in the department of Biochemistry, Bangabandhu Sheikh Mujib Medical University, Dhaka, Bangladesh. Sixty six postmenopausal women with central obesity and age matched 56 nonobese postmenopausal women were included in the study. Central obesity was defined having waist hip ratio more than 0.8 and BMI $<25.0$. All statistical analyses were done by SPSS 18.0. p values $<0.05$ were considered significant. Results: Statistically no significant difference was observed between the central obese women and nonobese women in lipid profile parameters. But AIP was found significantly higher in postmenopausal central obese women. Conclusion: Central obese postmenopausal women may be at higher risk of cardiovascular events compared with postmenopausal nonobese women in spite of no difference in lipid profile parameters as their AIP values are significantly different.
\end{abstract}

Key words: Atherogenic index of plasma (AIP); central obesity; postmenopausal; nonobese.

\section{INTRODUCTION}

Postmenopausal overweight and obesity may be clustered with hypertension, diabetes mellitus, coronary heart disease (CHD) and all-cause mortality ${ }^{1-2}$. Following menopause, adverse changes in lipid profile occur and the levels of several coagulation factors increase ${ }^{3}$.

TMJ ankylosis is an affliction that causes untold misery to many patients' particularly young adults. TMJ ankylosis is a very distressing structural condition that denies the victim the benefit of normal diet and opportunities in career that require normal speech ability. It also causes severe facial disfigurement that aggravates psychological stress ${ }^{5}$.

The lipid profile is a group of tests that are often done together to determine risk of CHD. It includes total cholesterol (TC), HDL-cholesterol, LDL-cholesterol and triacylglycerol (TAG). It is used to guide health care providers in decision making as to how a person at risk should be treated. The scenario of the lipid profile is considered along with other known risk factors of CHD to develop a plan of treatment and follow-up ${ }^{4}$. 
It is well known that in pre-menopausal women the incidence of cardiovascular events is lower than in men of the same age and after menopause cardiovascular morbidity and mortality in women become similar to that of man indicating that female sex hormones play an important protective role upon the vasculature. The prevalence of obesity and overweight is also higher in postmenopausal women than that in men of comparable age . $^{5}$.

Obesity is a term commonly used to describe individual with increased body fat. It is associated with an increased risk of atherosclerosis, diabetes mellitus and gall bladder disease. Normal fat content of body is considered to be $12-18 \%$ of body weight in men and $18-25 \%$ of body weight in women. Obesity is commonly said to be present when body fat content is more than $20 \%$ and $25 \%$ of body weight in men and women respectively. A value that correlates better with body fat is the body mass index (BMI) ${ }^{6}$. Individuals with BMI between 25 and 29.9 are overweight, and BMI ${ }^{3} 30$ are defined as obese ${ }^{7}$.

There are two major types of fat distribution in adult obese ${ }^{8}$.

1. Some adults store their fat mainly around the hips and thigh, which gives them a pear shape known as gynoid distribution; this is a characteristic of women.

2. The second type found in both sexes is the storage of fat primarily in the abdomen, producing an 'apple' shape known as android distribution.

Excess fat located in the central abdominal area of the body is associated with a greater risk for hypertension, insulin resistance, diabetes, dyslipidaemia and coronary heart disease. Android fat distribution is defined by waist to hip ratio (WHR) more than 0.8 for women and more than 1 for men?

Through the effect of menopausal transition, the morbidity and mortality of cardiovascular diseases in women are increased. Lack of the oestrogen protection is presumed to be the major reason. However, several other physiological changes (such as aging effect, increased body weight or android pattern of body fat distribution, decreasing resting metabolic rate and physical activity etc.) which develop during menopause may also influence the risk of cardiovascular disease. Among these factors the android pattern of body fat distribution seems to be the major issue. The android body fat distribution, glucose intolerance, hyperlipidaemia and hypertension appear to be clustered together in the same subject?.

The metabolic phenotype of postmenopausal women, which includes an increased tendency for body fat deposition in the abdominal region, suggests that insulin resistance may underlie the characteristic features of postmenopausal dyslipidaemia. Adverse effects of insulin resistance on lipid metabolism, with consequent effects on circulating TAG concentrations, may be the primary metabolic defects that lead to low HDL-cholesterol and increased prevalence of small dense LDL which are the key features of the atherogenic lipoprotein phenotype. Greater tendency for central fat deposition after the menopause may be particularly relevant to the higher incidence of CHD in postmenopausal women.
Although central obesity has been shown to be a strong risk factor of CHD for both men and women, studies in women generally produce values for relative risk that are higher than those found in $\operatorname{men}^{10}$.

The possibility of raised TAG as a key feature of the lipid disturbance that leads to increased risk of CHD after the menopause is supported by the fact that raised TAG is more strongly associated with CHD risk in women than men ${ }^{11}$.

Obesity is commonly regarded as an important contributor to the development of hyperlipidaemia on the basis that cross-sectional studies have documented statistically significant, although modest, associations between lipid levels and various estimates of obesity. Vague et al introduced the 'masculine differentiation index' to distinguish between 'android' and 'gynoid' obesity ${ }^{12}$. He found that a predominance of fat in the upper body (android obesity) was associated with metabolic disturbances, while a predominance of fat in the lower body (gynoid obesity) was associated only with problems such as abdominal pressure and locomotor difficulty. Following menopause fat is increasingly deposited in the upper body region which is associated with low HDL-cholesterol, high apolipoprotein-B and high triglycerides ${ }^{13}$. Abdominal obesity has been linked to significant metabolic abnormalities including insulin resistance, hyperinsulinaemia, and elevated TAG levels as well as increased incidence of hypertension, glucose intolerance and diabetes mellitus. Abdominal adiposity as measured by waisthip ratio (WHR), is an independent risk factor for CHD in men and perhaps also in women ${ }^{14}$.

Waist circumference and WHR are important indicators of cardiovascular risk even after adjustment for BMI. The increased visceral fat mass associated with increased waist circumference is largely the result of overall obesity, whereas in case of an increased WHR, the increase in visceral fat is due to other factors as well ${ }^{15}$. The prevalence of obesity is increasing worldwide. Cardiovascular disease (CVD) remains the major cause of death in postmenopausal women. Before menopause, women are relatively protected from ischaemic heart disease and thromboembolism by their circulating oestrogen, but this protection is lost after menopause ${ }^{3}$.

A lot of work has been done on the relationship between TG and HDL-C, and it has been shown that the ratio of TG to HDL-C is a strong predictor of myocardial infarction ${ }^{16}$. Atherogenic index of plasma (AIP) calculated as log (TG/HDLC) has been used as some practitioners as a significant predictor of atherosclerosis ${ }^{17-19}$. Application of AIP as a predictor of cardiovascular diseases may offer new insights.

So far we know, no study has been done in our population addressing AIP in postmenopausal women. Therefore, we designed this study to find out AIP in postmenopausal women and to compare it between postmenopausal women with central obesity and postmenopausal nonobese women. 


\section{MATERIALS \& METHODS}

This cross sectional study was done in the department of Biochemistry, Bangabandhu Sheikh Mujib Medical University (BSMMU), Dhaka, Bangladesh. Sixty six postmenopausal women with central obesity and age matched 56 nonobese postmenopausal women were included in the study. The subjects were selected by nonrandom purposive sampling from outpatient departments of BSMMU, Dhaka, Dhaka Medical College Hospital, Dhaka, Bashail and Shakhipur Upazilla Health Complexes, Tangail and different places of Dhaka City. Permission for the study was taken from the concerned authorities. All the subjects included in the study were informed of the purpose of the study. Written consent was taken after detailed explanation about the study.

Central obesity was defined having WHR $>0.8$. Postmenopausal women with diabetes mellitus, alcoholism, chronic renal failure, nephritis, nephrotic syndrome, myocardial infarction, hypertension, hypothyroidism and BMI 25 and subjects with TAG $>400 \mathrm{mg} / \mathrm{dL}$ were excluded from the study. After selection of the subjects, $4 \mathrm{~mL}$ of blood specimen was collected from each of them in fasting condition with all aseptic precautions for estimation of serum TC, TAG and HDLcholesterol levels. LDL-cholesterol level was calculated by applying Friedewald's formula. AIP was calculated as $\log$ of TAG/HDL-C ratio.

All statistical analyses were done by SPSS 18.0. Unpaired Student's $t$ test and Mann-Whitney $U$ test were done to compare the values between groups. p values $<0.05$ were considered significant.

\section{RESULTS}

The mean \pm SD of age of the postmenopausal women with central obesity was $56.21 \pm 9.78$ years and that of nonobese controls was $57.75 \pm 9.52$ years. Table I shows the comparison of serum lipid parameters between postmenopausal centrally obese cases and nonobese controls. Statistically there was no difference between the two groups in total cholesterol, triacylglycerol, HDL-cholesterol and LDL-cholesterol levels. Table II shows the comparison of AIP between two groups. The mean \pm SD of AIP of centrally obese and nonobese groups were $0.274 \pm 0.22$ and $0.178 \pm 0.19$ respectively. AIP values in cases differed significantly from those of nonobese controls.

Table I: Comparison of serum lipid parameters between postmenopausal centrally obese cases and nonobese controls $(\mathrm{N}=122)$

\begin{tabular}{lllll}
$\begin{array}{l}\text { Lipid parameters } \\
(\mathrm{mg} / \mathrm{dL})\end{array}$ & $\begin{array}{l}\text { Cases }(\mathrm{n}=66) \\
\text { Mean } \pm \mathrm{SD}\end{array}$ & $\begin{array}{l}\text { Controls }(\mathrm{n}=56) \\
\text { Mean } \pm \mathrm{SD}\end{array}$ & $\mathrm{t}$ values & $\mathrm{p}$ values \\
Total cholesterol & $196.05 \pm 50.94$ & $185.55 \pm 40.95$ & 1.239 & $>0.05$ \\
Triacylglycerol & $136.52 \pm 54.62$ & $120.79 \pm 46.39$ & 1.697 & $>0.05$ \\
HDL-cholesterol & $31.08 \pm 9.20$ & $33.57 \pm 7.21$ & -1.645 & $>0.05$ \\
LDL-cholesterol & $136.88 \pm 50.47$ & $127.79 \pm 41.68$ & 1.073 & $>0.05$ \\
\hline
\end{tabular}

Table II: Comparison of AIP between postmenopausal centrally obese cases and nonobese controls $(\mathrm{N}=122)$

$\begin{array}{lccc}\text { Groups } & \text { Median } & \begin{array}{c}\text { Mann-Whitney } \\ \text { U value }\end{array} & \mathrm{p} \text { value } \\ & & 1386.00 & <0.05 \\ \text { Central obese }(\mathrm{n}=66) & 0.255 & & \\ \text { Nonobese }(\mathrm{n}=56) & 0.175 & & \end{array}$

\section{DISCUSSION}

Obesity is a well documented separate risk factor for metabolic and vascular disease, which may reduce life expectancy for overweight people ${ }^{20}$. Menopause tends to be associated with an increased risk of obesity and a shift to an abdominal fat distribution with associated increase in health risk $^{21}$. In this study we have measured serum lipid profile in 66 cases of postmenopausal central obese women and 56 nonobese control postmenopausal women. We found that the values of TC, TAG and LDL- cholesterol had trend to increase and the value of HDL-cholesterol had trend to decrease in central obese cases. But no significant difference was found in these parameters between the groups. However, this finding does not support other similar studies ${ }^{22-24}$.

Many longitudinal studies have shown that TAG level increases with transition through the menopause and the increase in TAG also appears early in the postmenopausal period. Poehlman et al found that prospective transition to postmenopause was associated with a $16 \%$ increase in $\mathrm{TAG}^{25}$. It was observed in most studies that total HDL-cholesterol level falls slightly with menopause, whereas other blood lipids had no change. Increasing TAG with menopause may be related to the fact that TAG levels are highly correlated with increasing abdominal fat content and insulin resistance ${ }^{26}$. Carr observed that elevated LDL-cholesterol is not a feature of dyslipidaemia in case of postmenopausal women with abdominal obesity ${ }^{27}$.

In this study WHR was used as indicator of central obesity. In a small study of Swedish men, it was observed that a high waistto-hip ratio after adjustment for age and BMI was associated with an increased visceral fat area and a decreased thigh muscle $\operatorname{area}^{28}$.

In this study, there is no significant difference in lipid profile parameters between the postmenopausal central obese women and postmenopausal nonobese women. But significant difference $(p<0.05)$ was found in AIP between these groups. AIP is a significant predictor of atherosclerosis. So, although no difference was observed regarding lipids between the groups, yet central obese postmenopausal women are at higher risk of cardiovascular events compared with postmenopausal nonobese women as their AIP values are significantly different However, more studies with larger sample size are recommended. Extensive studies should be done on central obesity in men, women and children as obesity is a global problem now-a-days. We recommend creating awareness regarding metabolic complications of central obesity in postmenopausal women as well as in general population.

\section{CONCLUSION}

There was an important limitation in this study. We could not include premenopausal women in the study. It would have been better if we could do it and compare the lipid profile and AIP among premenopausal, postmenopausal central obese and postmenopausal nonobese women.

\section{DISCLOSURE}

All the authors declared no competing interest. 


\section{REFERENCES}

1. Berry EM, Brejezinski A, Dubnov G. Weight control and the management of obesity after menopause: the role of physical activity. Maturitas 2003; 44(2): 89-101.

2. Gilling L, Suwattee P, DeSouza C, Asnani S, Fonseca V. Effects of the thiazolidinediones on vascular risk factors. Am J Cardiovasc Drugs 2002; 2: 149-156.

3. Basurto L, Hermandez M, Zarate A. The metabolic syndrome in postmenopausal women: clinical implication. Gac Med Mex 2003; 139(6): 625-628.

4. Libby P. Prevention and treatment of atherosclerosis. In: DL Kasper, Fauci AS, Longo DL, Braunwald E, Hauser SL, Jameson JL (eds). Harrison's principles of internal medicine. $16^{\text {th }}$ edn. New York: McGraw-Hill, 2005; 1430-1433.

5. Ruppelli A. Hypertension and obesity after the menopause. J Hypertens 2002; 20(2): S26-28.

6. Gannong WF. Energy balance, metabolism and nutrition. In: Review of medical physiology. $20^{\text {th }}$ edn. New York: McGraw-Hill Companies, 2001; 271306.

7. Obesity. In: Champe PC, Harvey RA, Ferrier DR (eds). Lippincott's illustrated reviews: Biochemistry. $3^{\text {rd }}$ edn. Philadelphia: Lippincott Williams \& Wilkins, 2005; 347-354.

8. Frier BM, Truswell AS, Shepherd J, de Looy A, Jung R. Diabetes mellitus, and nutritional and metabolic disorders. In: Haslett C, Chilver ER, Hunter JAA, Boon NA (eds). Davidson's principles and practice of medicine. $18^{\text {th }}$ edn. London: Churchill Livingstone, 1999; 471-542.

9. Chang CJ, Wu CH, Yao WJ, Yang YC, Wu JS, Lu FH. Relationship of age, menopause and central obesity on cardiovascular disease risk factor in Chinese women. International Journal of Obesity 2000; 24: 1699-1704.

10. Loverove JA, Sliva R, Wright JW, Williams CM. Adiposity, insulin and lipid metabolism in post-menopausal women. International Journal of Obesity 2002; 26: 475-486.

11. Lovegrove JA, Silva KDRR, Wright JN, Williams CM. Adiposity, insulin and lipid metabolism in postmenopausal women. International Journal of Obesity 2002; 26(4): 475-486.

12. Vague J. The degree of masculine differentiation of obesities: a factor determining predisposition to diabetes, atherosclerosis, gout, and uric calculous disease. Am J Clin Nutr January 1956; 4(1): 20-34.

13. Gower BA, Nagy TR, Goran MI, Toth MJ, Poehlman ET. Fat distribution and plasma lipid-lipoprotein concentrations in pre- and postmenopausal women. International Journal of Obesity 1998; 22: 605-611.

14. Rexrode KM, Carey VJ, Hennekens CH, Walters EE, Colditz GA, Stampfer MJ et al. Abdominal adiposity and coronary heart disease in women. JAMA 1998; 280(21): 1843-1848.

15. Rexrode KM, Carey VJ, Hennekens CH, Walters EE, Colditz GA, Stampfer MJ et al. Abdominal adiposity and coronary heart disease in women. JAMA 1999; 281: 2284-2285.

16. Gaziano JM, Henne kens CH, O’Donnell CJ, Breslow JL, Burning JE. Fasting triglycerides, high density lipoprotein, and risk of myocardial infarction. Circulation 1997; 96: 2520-2525.

17. Dobiasova M, Frohlich J. The plasma parameter $\log (\mathrm{TH} / \mathrm{HDL}-\mathrm{C})$ as an atherogenic index: correlation with lipoprotein particle size and esterification rate in apo-B lipoprotein-depleted plasma. Clin Biochem 2001; 34: 583588.

18. Tan MH, Johns D, Glazer NB. Pioglitazone reduces atherogenic index of plasma in patients with type 2 diabetes. Clin Chem 2004; 50: 1184-1188.

19. Parinita K. Study of serum lipid profile in individuals residing in and around Nalgonda. Int J Pharm Bio Sci 2012; 2: 110116.

20. Silberbauer K. Cardiovascular sequele and risk of obesity. Acta Med Austriaca 1998; 25(4-5): 133-135.

21. Lovejoy PC. The menopause and obesity. Prim Care 2003; 30(2): 317-325.

22. Bruzell JD, Hokanson JE. Low-density and high-density lipoprotein subspecies and risk for premature coronary artery disease. Am J Med 1999; 107: 165.

23. Bikkina M, Larson MG, Levy D. Prognostic implications of asymptomatic ventricular arrhythmias: the Framingham Heart Study. Ann Intern Med 1992; 117: 990-996.

24. Lee ET, Cowan LD, Welty TK, Sievers M, Howard WJ, Oopik A et al. All-cause morality and cardiovascular disease mortality in three American Indian populations, aged 45-74 years, 1984-1988: the Strong Heart Study. Am. J. Epidemiol. 1998; 147(11): 995-1008.

25. Poehlman ET, Toth MJ, Gardner AW. Changes in energy balance and body composition at menopause: a controlled longitudinal study. Ann Intern Medicine 1995; 123: 673-675.

26. Carr MC. The emergence of the metabolic syndrome with menopause. J Clin Endocrinol Metab 2003; 88(6): 2404-2411.

27. Carr MC, Brunzell JD. Abdominal obesity and dyslipidemia in the metabolic syndrome. The Journal of Clinical Endocrinology \& Metabolism 2004; 89(6): 2601-2607.

28. Seidell JC, Bjorntorp P, Sjostrom L, Sannerstdt R, Krotkiewski M, Kvist H. Regional distribution of muscle and fat mass in men - New insight into the risk of abdominal obesity using computed tomography. Int J Obes 1989; 13: 289-303. 